\title{
Barriers to adherence to chronic obstructive pulmonary disease guidelines by primary care physicians
}

This article was published in the following Dove Press journal:

International Journal of COPD

4 March 2011

Number of times this article has been viewed

\author{
Gregory D Salinas' \\ James C Williamson' \\ Ravi Kalhan ${ }^{2}$ \\ Byron Thomashow ${ }^{3}$ \\ Jodi L Scheckermann ${ }^{4}$ \\ John Walsh ${ }^{5}$ \\ Maziar Abdolrasulnia' \\ Jill A Foster ${ }^{\prime}$ \\ 'CE Outcomes, LLC Birmingham, \\ AL, USA; ${ }^{2}$ Asthma-COPD Program, \\ Division of Pulmonary and Critical \\ Care Medicine, Northwestern \\ University Feinberg School of \\ Medicine, Chicago, IL, USA; ${ }^{3}$ Division \\ of Pulmonary, Allergy, Critical Care, \\ Department of Medicine, College \\ of Physicians and Surgeons, Columbia \\ University, New York, NY, USA; \\ ${ }^{4}$ Boehringer-Ingelheim Pharmaceuticals, \\ Inc., Ridgefield, CT, USA; ${ }^{5}$ COPD \\ Foundation, Miami, FL, USA
}

Purpose: Even with the dissemination of several clinical guidelines, chronic obstructive pulmonary disease (COPD) remains underdiagnosed and mismanaged by many primary care physicians (PCPs). The objective of this study was to elucidate barriers to consistent implementation of COPD guidelines.

Patients and methods: A cross-sectional study implemented in July 2008 was designed to assess attitudes and barriers to COPD guideline usage.

Results: Five hundred US PCPs (309 family medicine physicians, 191 internists) were included in the analysis. Overall, $23.6 \%$ of the surveyed PCPs reported adherence to spirometry guidelines over $90 \%$ of the time; $25.8 \%$ reported adherence to guidelines related to long-acting bronchodilator (LABD) use in COPD patients. In general, physicians were only somewhat familiar with COPD guidelines, and internal medicine physicians were significantly more familiar than family physicians $(P<0.05)$. In a multivariate model controlling for demographics and barriers to guideline adherence, we found significant associations with two tested guideline components. Adherence to spirometry guidelines was associated with agreement with guidelines, confidence in interpreting data, ambivalence to outcome expectancy, and ability to incorporate spirometry into patient flow. Adherence to LABD therapy guidelines was associated with agreement with guidelines and confidence in gauging pharmacologic response.

Conclusions: Adherence to guideline recommendations of spirometry use was predicted by agreement with the recommendations, self-efficacy, perceived outcome expectancy if recommendations were adhered to, and resource availability. Adherence to recommendations of LABD use was predicted by agreement with guideline recommendations and self-efficacy. Increasing guideline familiarity alone may have limited patient outcomes, as other barriers, such as low confidence and outcome expectancy, are more likely to impact guideline adherence.

Keywords: COPD, primary care, barriers, guideline adoption

\section{Introduction}

Chronic obstructive pulmonary disease (COPD) is the fourth leading cause of morbidity and mortality in the US and affects more than 12 million Americans. This respiratory disease is commonly evaluated and managed by primary care physicians (PCPs), particularly when symptoms are of mild-to-moderate severity. ${ }^{1}$ Several clinical practice guidelines offer strategies to optimize care for patients with COPD in the primary care setting. These evidence-based resources are free and easily accessible via the Internet. Many have been recently issued or updated, integrating new scientific findings and reflecting the availability of emerging therapeutic options.

Despite the availability of guidelines, PCPs often manage COPD in a manner that is discordant with recommendations. To a degree, this may reflect limited awareness of 
recommendations, as many PCPs are unfamiliar with COPD guidelines. ${ }^{2,3}$ Yet even among physicians who have some guideline familiarity, practice patterns are often inconsistent with guideline recommendations. . $^{2,3}$

Guideline implementation to facilitate accurate COPD diagnosis is of particular concern. Current guidelines universally advocate the use of spirometry to confirm a COPD diagnosis and to facilitate early intervention. This stance is consistent with diagnostic directives that date back more than 35 years. ${ }^{4}$ Despite its longevity, physician adherence to this recommendation is subobptimal. COPD is often underdiagnosed and misdiagnosed in the primary care setting. ${ }^{5}$ Marked underutilization of spirometry testing has been well documented and is thought to be a contributing factor. ${ }^{2,3,6,7}$ Lack of spirometry access undoubtedly contributes to low utilization and is a significant problem for some primary care practice. Interventions have been designed to overcome this barrier by providing equipment and training but have been inconsistent in improving spirometry use. ${ }^{8,9}$ Other influences and barriers may be restraining spirometry use and need to be better defined and targeted.

Cabana et al have developed a framework that may be helpful in explaining and identifying key determinants of guideline adherence by physicians. ${ }^{10}$ Their model was originally developed to identify determinants of guideline adoption in pediatric asthma, ${ }^{11}$ but it has been extensively applied to elicit potential levers for performance improvement. ${ }^{12,13}$ The Cabana model examines commonly studied determinants such as guideline familiarity and barriers to guideline adoption. In addition, the model explores perceptual influences on behavior, such as attitudes regarding the guideline source, as well as the expected benefits of implementing specific recommendations.

This framework was applied in the present study to explore determinants of COPD guideline adherence or lack thereof. Models designed for this study used the evidencebased guideline developed by the Global Initiative for Chronic Obstructive Lung Disease (GOLD) as a benchmark. ${ }^{14}$ The primary model developed for this study centered on diagnostic spirometry use. Directives to use spirometry to confirm COPD diagnosis have been relatively stable for an extended period, and there is a considerable amount of literature on spirometry use to inform the model. As a secondary focus, we also explored the use of bronchodilator agents to treat COPD symptoms. GOLD guidelines recommend inhaled bronchodilators as a cornerstone of COPD symptom management; however, PCPs often turn to other agents as first-line COPD therapy. ${ }^{1,2}$ Optimal pharmacotherapy for
COPD is a more dynamic area as a result of emerging trial data and therapeutic options.

The use of the Cabana framework to explore these two aspects of COPD care enables several behavioral influences to be examined simultaneously and may provide valuable insight about their relative importance. This information is expected to facilitate the development of more effective educational and quality improvement interventions in COPD care.

\section{Methods \\ Development and distribution of survey instrument}

A survey instrument was developed to explore determinants of PCP adherence to GOLD guideline recommendations on diagnostic spirometry and long-acting bronchodilator (LABD) use. The instrument's domains drew on the Cabana guideline adherence framework. Self-reported adherence to GOLD recommendations was assessed with two questions on routine clinical practice behaviors. Physicians were asked to rate how often they "order spirometry when patients report symptoms that lead you to suspect COPD" and how often they "recommend using an inhaled longacting bronchodilator daily for patients with COPD and mild exertional dypnea". Adherence was measured using five frequency categories ( $\leq 25 \%$ of the time, $26 \%-50 \%$ of the time, $51 \%-75 \%$ of the time, $75 \%-90 \%$ of the time, and $\geq 91 \%$ of the time).

Physicians were asked to rate their familiarity and perceptions regarding the GOLD guidelines, as well as their agreement with specific GOLD recommendations. Physicians were also asked to rate the perceived helpfulness (outcome expectancy) and their confidence (self-efficacy) in implementing the two guideline recommendations of interest. The survey used a 10-point Likert scale for respondents to indicate familiarity with guidelines, outcomes expectancy, and self-efficacy (1, not at all; 10, extremely). A 7-point Likert scale was used to measure agreement with guideline statements (1, strongly disagree; 4, neutral; 7, strongly agree). Because of space limitations, assessment of barriers focused only on spirometry testing. Physicians were asked whether they had used an onsite spirometer and where they typically send patients who need spirometry testing. They were also asked to indicate, in a dichotomous manner, whether potential barriers hindered their ability to confirm a COPD diagnosis using spirometry. Demographic information about physicians and their practice was also collected. 
Primary care and pulmonology physicians with recognized expertise in COPD provided guidance during survey development. As an additional quality control measure, the survey was piloted with PCPs using a cognitive interview process. This step identified potential areas of ambiguity within the instrument and ensured its relevance to community-based clinical practice.

The survey instrument was distributed by email and fax in July 2008 to 11,100 PCPs randomly selected from the American Medical Association (AMA) Physician Masterfile. A small monetary incentive was offered for completion of the survey. The first 500 individuals who responded to the invitation and met the criteria for inclusion were accepted into the study. A power calculation was conducted to determine the sufficient sample size (confidence interval of $95 \%$ ) to represent the US PCP population.

\section{Analysis}

Descriptive and inferential statistics were conducted on all items in the survey using Chi-square $\left(\chi^{2}\right)$ analysis to examine differences between family medicine and internal medicine physicians. Binary logistic regression was used to predict guideline adherence (SPSS ${ }^{\circledR}$, Version 17.0; SPSS Inc, Chicago, IL, USA). For the two guideline components analyzed, the dependent variable was each physician's selfreported level of guideline adherence. Independent variables included agreement with guideline statements, guideline familiarity level, self-efficacy and outcome expectancy of spirometry or LABD use, external barriers to spirometry, percentage of patients seen with COPD, gender, specialty, and years in practice. For analysis, physicians were considered to be guideline adherent if they implemented a guideline recommendation over $91 \%$ of the time, equal to the value set by Cabana et al. ${ }^{11}$ Values were considered significant when $P<0.05$.

\section{Results \\ Sample}

Table 1 shows the demographic data of the survey respondents. Most of the surveyed physicians practiced in a community setting. Internal medicine physicians saw, on average, five more patients per week with COPD than did family medicine physicians. The surveyed internal medicine physicians also had been in practice longer and were more likely to be male than the family medicine physicians. When compared with characteristics of US PCPs identified from the AMA Physician Masterfile, this sample had similar years in practice but a higher male representation.
Table I Characteristics of survey respondents

\begin{tabular}{|c|c|c|c|}
\hline & $\begin{array}{l}\text { Overall } \\
(n=500)\end{array}$ & $\begin{array}{l}\text { Family } \\
\text { medicine } \\
(n=309)\end{array}$ & $\begin{array}{l}\text { Internal } \\
\text { medicine } \\
(n=191)\end{array}$ \\
\hline Mean years in practice (SD) & I6.I (7.8) & $15.7(7.9)$ & $16.8(7.6)$ \\
\hline $\begin{array}{l}\text { Mean patients seen/week } \\
\text { with COPD (SD) }\end{array}$ & $19.2(20.8)$ & $17.2(16.5)$ & $22.5(26.1)$ \\
\hline Male $(\%)$ & 72.6 & 71.2 & 74.9 \\
\hline Work environment (\%) & & & \\
\hline $\begin{array}{l}\text { Community-based } \\
\text { private practice }\end{array}$ & 78.0 & 76.6 & 80.1 \\
\hline Academic practice & 5.0 & 4.5 & 5.8 \\
\hline $\mathrm{HMO}$ & 1.2 & 1.6 & 0.5 \\
\hline Hospital-owned practice & 11.8 & 11.4 & 12.6 \\
\hline Other & 4.0 & 5.8 & 1.0 \\
\hline
\end{tabular}

Abbreviations: COPD, chronic obstructive pulmonary disease; $\mathrm{HMO}$, health maintenance organization; SD, standard deviation.

\section{Guideline adherence}

A majority of the physicians agreed with guideline statements regarding spirometry and LABD use (Table 2). Over two-thirds (69.1\%) of PCPs agreed that when COPD is suspected, the diagnosis should be confirmed by spirometry; 78.4\% agreed that an LABD should be added for patients with stage 2-3 COPD whose dyspnea during daily activities is not relieved with an as-needed short-acting bronchodilator. However, only $23.4 \%$ of surveyed PCPs indicated that they "nearly always" ( $\geq 91 \%$ of the time) order spirometry when patients report symptoms suggestive of COPD. Also, only $25.8 \%$ of the PCPs "nearly always" recommend using an LABD daily for patients with COPD and mild exertional dyspnea.

\section{Guideline familiarity}

Respondents were asked to rate familiarity with various guidelines on a 10-point scale. Overall, PCPs were more familiar with GOLD guidelines than with American Thoracic Society (ATS)/European Respiratory Society (ERS) or American College of Physicians (ACP) guidelines. High levels of familiarity with GOLD, ATS/ERS, and ACP guidelines and ratings of $8-10$ on the 10 -point scale were more common with internal medicine physicians than with family medicine physicians (Figure 1). Nearly one-quarter (24.0\%) of PCPs were unfamiliar with GOLD guidelines, rating familiarity as $1-3$ on the 10 -point scale; $23.0 \%$ were unfamiliar with ACP guidelines. One-third (33.2\%) of respondents were unfamiliar with ATS/ERS guidelines. As a comparison, approximately three-quarters of internal medicine and family medicine physicians were very familiar with the Seventh Report of the Joint National Committee on Prevention, Detection, Evaluation, and Treatment of High 
Table 2 Adherence and attitudes toward chronic obstructive pulmonary disease (COPD) guidelines

\begin{tabular}{|c|c|c|c|c|}
\hline & Overall & Family medicine & Internal medicine & $P$ \\
\hline \multicolumn{5}{|c|}{ In your routine clinical practice, how often do you do each of the following?a } \\
\hline $\begin{array}{l}\text { Order spirometry when patients report symptoms that lead } \\
\text { you to expect COPD }\end{array}$ & $23.6 \%$ & $23.7 \%$ & $23.0 \%$ & 0.12 \\
\hline $\begin{array}{l}\text { Recommend using an inhaled long-acting bronchodilator } \\
\text { daily for patients with COPD and mild exertional dyspnea }\end{array}$ & $25.8 \%$ & $23.9 \%$ & $28.8 \%$ & 0.68 \\
\hline \multicolumn{5}{|l|}{ Agreement with guideline statements ${ }^{b}$} \\
\hline $\begin{array}{l}\text { When COPD is suspected, the diagnosis should be } \\
\text { confirmed by spirometry }\end{array}$ & $69.2 \%$ & $68.9 \%$ & $69.5 \%$ & 0.92 \\
\hline $\begin{array}{l}\text { For patients with stage } 2-3 \text { COPD whose dyspnea during } \\
\text { daily activities is not relieved with as-needed short-acting }\end{array}$ & $78.2 \%$ & $79.6 \%$ & $76.4 \%$ & 0.43 \\
\hline
\end{tabular}

Notes: "Values indicate percentage of physicians who indicated that they "nearly always" do this action ( $91 \%-100 \%$ of the time); ${ }^{\circ} \mathrm{Values}$ indicate percentage of physicians who "agree" or "strongly agree" with the statements (6-7 on a 7-point scale).

Blood Pressure (JNC 7) hypertension guidelines, rating familiarity as $8-10$. Physicians who care for more patients with COPD were more likely to be familiar with all COPD guidelines. Physicians who had been in practice for 15 years or less were more likely to be familiar with ATS/ERS guidelines but not GOLD guidelines.

\section{Attitudes regarding guideline recommendations}

A majority of PCPs reported high confidence (8-10 on the 10-point scale) with regard to spirometry and LABD use. However, of these statements, PCPs gave lower ratings to their confidence in interpreting spirometry results and recommending an optimal therapeutic regimen for a patient with established COPD and mild exertional dyspnea (Figure 2A). Internal medicine physicians reported significantly higher confidence than family physicians in both choosing the appropriate pulmonary function test for COPD $(75.8 \%$ vs

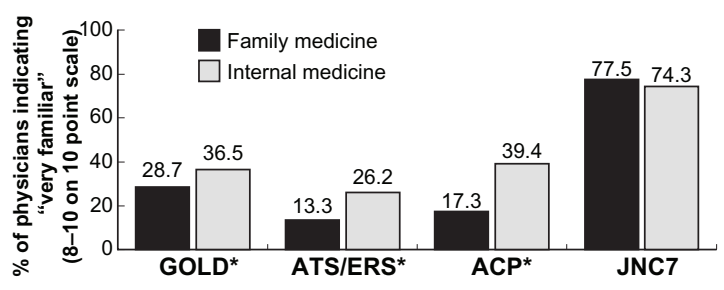

Figure I Familiarity with clinical practice guidelines. Surveyed physicians indicated their familiarity with various clinical practice guidelines. The percentages of physicians who rated themselves as "very familiar" (rated 8-10 on a 10-point scale) are shown. Internal medicine physicians are more familiar with GOLD, ATS/ERS, and ACP COPD guidelines than family medicine physicians. However, familiarity with the COPD guidelines is much less than familiarity with the JNC 7 hypertension guidelines.

Note: *Significance between familiarity of specialties $(P<0.05)$.

Abbreviations: ACP, American College of Physicians; ATS, American Thoracic Society; COPD, chronic obstructive pulmonary disease; ERS, European Respiratory Society; GOLD, Global Initiative for Chronic Obstructive Lung Disease; JNC 7, Seventh Report of the Joint National Committee on Prevention, Detection, Evaluation, and Treatment of High Blood Pressure.
$64.7 \%, P=0.02)$ and interpreting spirometry data $(67.4 \% \mathrm{vs}$ $59.9 \%, P=0.02)$.

Most PCPs believed that spirometry testing is very helpful (rated 8-10) in confirming suspicion about a COPD diagnosis, but physicians were less sure that spirometry testing improves patient outcomes (Figure 2B). Most physicians believed that LABDs were helpful in increasing a patient's activity level and quality of life; just under half, however, were unsure that LABDs would reduce the risk of future COPD exacerbation (Figure 2C).

\section{External barriers to spirometry use}

PCPs indicated that there were considerable external barriers to obtaining confirmatory spirometry use, as shown in Table 3. Nearly half of physicians did not have a working spirometer in their practice, and nearly 1 in 5 cited inadequate access as a significant hindrance to spirometry testing, with the most common barrier attributed to lack of a working spirometer onsite. Internal medicine physicians were more likely than family physicians to encounter a patient's reluctance to undergo evaluation by spirometry.

\section{Relationship of barriers with COPD guideline adherence}

Logistic regression models were used to identify predictors of adherence to confirmatory spirometry testing and LABD use recommendations, as shown in Table 4. In adjusted analysis, independent predictors of PCP adherence to spirometry recommendations were agreement with the spirometry guideline statement (odds ratio [OR] 3.15), high confidence in spirometry data interpretation (OR 1.34), and an expectation that spirometry testing would confirm suspicion of COPD (OR 1.55). Physicians indicating an inability to integrate onsite spirometry into patient flow were $77 \%$ less 
A Confidence in own ability: To choose pulmonary function test for COPD To interpret data on FEV and FVC To recommend optimal therapeutic regimen To gauge response to pharmacotherapy
Family medicine

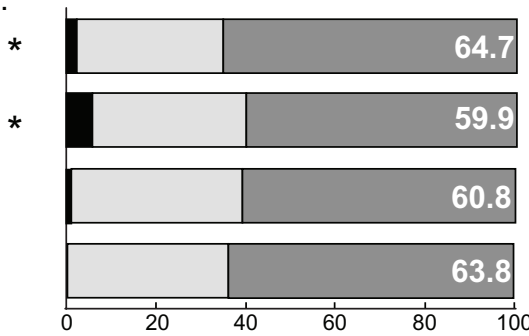

Internal medicine

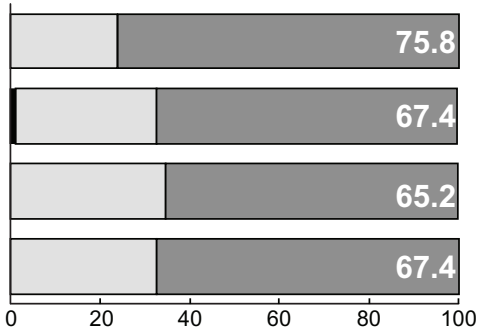

B For a patient with newly suspected COPD, how helpful is spirometry testing:

In confirming suspicion of COPD

In guiding therapeutic management

In improving patient health outcomes
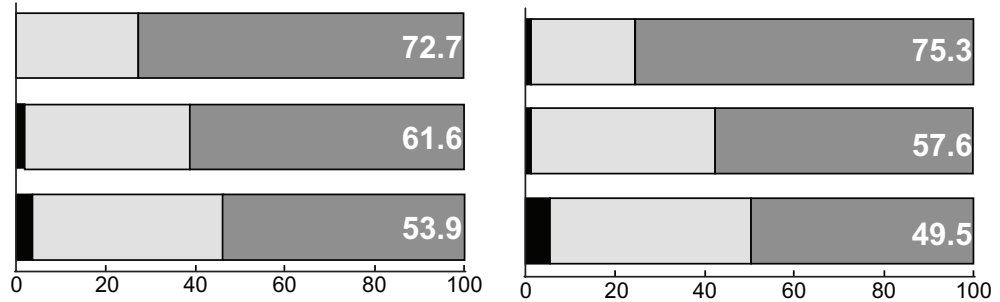

C For a patient with moderate suspected COPD, how helpful is regular use of a long-acting bronchodilator:

In reducing exertional dyspnea symptoms In reducing risk of future COPD exacerbations In increasing a patient's activity level In increasing a patient's quality of life
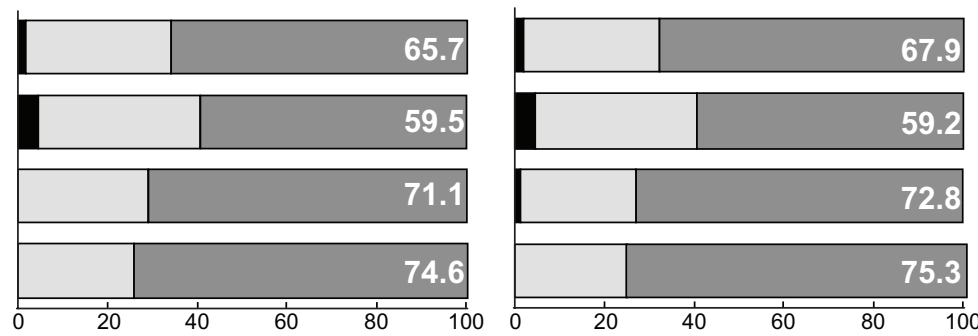

Rating scales: 1-3 (not confident/helpful)

4-7 (somewhat)

8-10 (very)

Figure 2 Primary care physician assessment of self-efficacy and outcome expectancy of spirometry and long-acting bronchodilator use. Surveyed physicians indicated their levels of self-efficacy $(\mathbf{A})$ represented by self-assessment of their own abilities, and outcome expectancy of spirometry (B) and long-acting bronchodilator use (C) defined by views on expected helpfulness. Values show percentages of the physicians who rated themselves as "very confident" or that spirometry/long-acting bronchodilators were "very helpful" in the given areas.

Note: *Statistical significance between family physicians and internists $(P<0.05)$.

Abbreviations: COPD, chronic obstructive pulmonary disease; $\mathrm{FEV}_{1}$, forced expiratory volume in I second; FVC, forced vital capacity.

likely to order spirometry (OR 0.23). The model examining determinants of LABD use showed that PCPs were more likely to adhere if they agreed with guideline statements on LABD use (OR 1.62) or were confident in gauging patient response to pharmacotherapy (OR 1.52). The percentage of patients seen with COPD, gender, specialty, or the number of years in practice had no significant association with guideline adherence for either measure.

\section{Discussion}

This study examined PCP attitudes and perceptions to the adherence to GOLD COPD practice guidelines. One main

Table 3 External barriers to spirometry usage ${ }^{a}$

\begin{tabular}{|c|c|c|c|c|}
\hline & Overall & Family medicine & Internal medicine & $\boldsymbol{P}$ \\
\hline Lack of working spirometer onsite & $46.8 \%$ & $46.6 \%$ & $47.6 \%$ & 0.85 \\
\hline Lack of spirometry testing nearby & $18.4 \%$ & $17.5 \%$ & $19.9 \%$ & 0.55 \\
\hline $\begin{array}{l}\text { Inability to integrate onsite } \\
\text { spirometry into patient flow }\end{array}$ & $35.6 \%$ & $36.9 \%$ & $33.5 \%$ & 0.50 \\
\hline $\begin{array}{l}\text { Inadequate reimbursement for } \\
\text { performing and/or interpreting spirom }\end{array}$ & $34.8 \%$ & $35.0 \%$ & $34.6 \%$ & 1.00 \\
\hline $\begin{array}{l}\text { Patient reluctance to be tested with } \\
\text { a spirometer }\end{array}$ & $42.4 \%$ & $38.8 \%$ & $48.2 \%$ & 0.04 \\
\hline Cost of spirometry testing to patient & $33.0 \%$ & $35.6 \%$ & $28.8 \%$ & 0.12 \\
\hline
\end{tabular}

Note: ${ }^{V}$ alues indicate percentage of physicians indicating these as barriers to confirming chronic obstructive pulmonary disease diagnosis using spirometry. 
Table 4 Logistic regression model of physician adherence to COPD guidelines (values indicate odds ratios [95\% confidence intervals])

\begin{tabular}{|c|c|c|}
\hline & Order spirometry & $\begin{array}{l}\text { Recommend daily long- } \\
\text { acting bronchodilator }\end{array}$ \\
\hline \multicolumn{3}{|l|}{ Agreement with guideline statements } \\
\hline $\begin{array}{l}\text { When COPD is suspected, the diagnosis should be } \\
\text { confirmed by spirometry }\end{array}$ & $3.15^{\mathrm{a}}(2.03-4.86)$ & $1.13(0.89-1.44)$ \\
\hline For patients with stage 2-3 COPD whose dyspnea during & $1.12(0.82-1.54)$ & $1.62^{\mathrm{b}}(1.16-2.27)$ \\
\hline \multicolumn{3}{|l|}{ daily activities is not relieved with as-needed short-acting } \\
\hline \multicolumn{3}{|l|}{ bronchodilator, a long-acting bronchodilator should be added } \\
\hline \multicolumn{3}{|l|}{ Familiarity with COPD guidelines } \\
\hline Global Initiative for Chronic Obstructive Lung Disease & $1.04(0.91-1.18)$ & $1.02(0.91-1.15)$ \\
\hline American Thoracic Society & $1.16(0.97-1.39)$ & I.0I (0.87-I.I7) \\
\hline American College of Physicians & $0.96(0.81-1.13)$ & I.II (0.96-I.28) \\
\hline \multicolumn{3}{|l|}{ Self-efficacy } \\
\hline \multicolumn{3}{|l|}{ test for COPD } \\
\hline Confidence in interpreting data on $\mathrm{FEV}_{1}$ and FVC & $1.34^{\mathrm{a}}(1.0 \mathrm{I}-1.78)$ & \\
\hline Confidence in recommending an optimal therapeutic regimen & & $1.03(0.74-1.42)$ \\
\hline Confidence in gauging response to pharmacotherapy & & $1.52^{\mathrm{a}}(1.05-2.20)$ \\
\hline \multicolumn{3}{|l|}{ Outcome expectancy } \\
\hline Spirometry testing in conforming suspicion of COPD & $1.55^{\mathrm{a}}(1.16-2.07)$ & \\
\hline Spirometry testing in guiding therapeutic management & $0.88(0.69-1.13)$ & \\
\hline Spirometry testing in improving patient health outcomes & $0.90(0.73-1.10)$ & \\
\hline Long-acting bronchodilator in reducing exertional & & $0.93(0.69-1.26)$ \\
\hline \multicolumn{3}{|l|}{ dyspnea symptoms } \\
\hline Long-acting bronchodilator in reducing risk of future & & $0.96(0.80-1.16)$ \\
\hline \multicolumn{3}{|l|}{ COPD exacerbations } \\
\hline Long-acting bronchodilator in increasing a patient's & & $1.17(0.73-1.86)$ \\
\hline \multicolumn{3}{|l|}{ activity level } \\
\hline Long-acting bronchodilator in increasing a patient's & & $\mathrm{I} .14(0.7 \mathrm{I}-\mathrm{I} .8 \mathrm{I})$ \\
\hline \multicolumn{3}{|l|}{ quality of life } \\
\hline \multicolumn{3}{|l|}{ External barriers to spirometry use } \\
\hline Lack of working spirometer onsite & $\mathrm{I} .42(0.76-2.66)$ & \\
\hline Lack of spirometry testing nearby & $1.27(0.54-2.98)$ & \\
\hline Inability to integrate onsite spirometry into patient flow & $0.23^{b}(0.11-0.46)$ & \\
\hline Inadequate reimbursement for performing and/or & $0.80(0.44-1.45)$ & \\
\hline \multicolumn{3}{|l|}{ interpreting spirometry } \\
\hline Patient reluctance to be tested with a spirometer & $0.96(0.55-1.67)$ & \\
\hline Cost of testing to patient & $0.93(0.52-1.66)$ & \\
\hline \multicolumn{3}{|l|}{ Demographics } \\
\hline Percentage of patients with COPD & I.0I (0.99-1.04) & $1.00(0.98-1.02)$ \\
\hline Gender & $0.86(0.46-1.61)$ & $1.32(0.78-2.24)$ \\
\hline Specialty & $0.76(0.42-1.37)$ & $0.99(0.60-1.62)$ \\
\hline Years in practice & $0.98(0.95-1.02)$ & $1.00(0.97-1.03)$ \\
\hline
\end{tabular}

Notes: ${ }^{\text {a }} \mathrm{P}<0.05$; ${ }^{\mathrm{b}} \mathrm{P}<0.01$.

Abbreviations: COPD, chronic obstructive pulmonary disease; $\mathrm{FEV}_{1}$, forced expiratory volume in I second; FVC, forced vital capacity.

finding was that only 1 of 4 PCPs adhered to either guideline recommendation on spirometry and LABD use more than $90 \%$ of the time. Adherence to guideline recommendations of spirometry use was predicted by agreement with the recommendations, self-efficacy, perceived outcome expectancy if recommendations were adhered to, and resource availability. Adherence to recommendations of LABD use was predicted by agreement with guideline recommendations and self-efficacy. Survey respondents demonstrated greater awareness of COPD practice guidelines disseminated by GOLD than to those released by the ATS/ERS. Internal medicine physicians indicated more familiarity with COPD guidelines than family physicians, possibly in part because internal medicine physicians may care for more patients with COPD than family practitioners. Internists were most familiar with the ACP guidelines.

Less than one-third (31.6\%) of PCPs cited high familiarity with the GOLD guidelines. This finding rests in stark contrast with the more than three-quarters $(76.4 \%)$ of respondents who indicated high familiarity with JNC 7 hypertension 
guidelines. Although the greater degree of familiarity with hypertension guidelines may in part be attributed to the higher prevalence of hypertension than of COPD, the disparity between guideline awareness for these two common disease processes suggests that there may be room for improvement in the dissemination of COPD guidelines.

However, increased awareness and dissemination of guidelines alone may not necessarily translate into greater incorporation of such guidelines into practice. A study by Christian et al examining quality of cardiovascular disease preventive care found that self-reported incorporation of relevant guidelines was lower than awareness levels..$^{15}$ In their original paper on pediatric asthma guidelines, Cabana et al found that some element of their model applied to nonadherence to every guideline component they tested, ${ }^{11}$ including familiarity. In our model, familiarity with any guideline did not impact adherence to guideline statements. There was also discordance between self-reported confidence in pulmonary function test selection and the importance given to spirometry. More than two-thirds (69\%) of PCPs indicated that they were extremely confident in choosing the appropriate pulmonary function test to determine whether COPD is present, and a majority (62.6\%) cited high confidence in ability to interpret spirometry results. Furthermore, although $60 \%$ of PCPs indicated that spirometry testing would be extremely helpful in guiding therapeutic management in a patient with newly suspected COPD, less than one-third (29.6\%) strongly agreed that a suspected diagnosis of COPD should be confirmed by spirometry. Only about half $(52.3 \%)$ of PCPs indicated that spirometry would be extremely helpful in improving health outcomes in a patient with newly suspected COPD.

It should be noted that not all COPD practice guidelines unequivocally support spirometry. The ATS/ERS guidelines support the use of spirometry in primary care practice, whereas the ACP guidelines state that there is insufficient evidence for the use of spirometry for screening. ${ }^{16,17}$ One trial has examined the use of a combined nurse and physician intervention to increase and improve spirometry performance but found no difference in outcomes of care between treatment and usual care groups. ${ }^{18}$ The correct diagnosis of COPD remained very low ( $8 \%$ in both groups). Another trial is currently underway to examine a combined physiciannurse intervention. ${ }^{19}$

Our study also examined physician perspectives regarding therapy for COPD. Nearly two-thirds of PCPs indicated high confidence in recommending an optimal therapeutic regimen and gauging response to pharmacotherapy in a patient with established COPD and mild exertional dyspnea. Nonetheless, substantially less than half (39.7\%) of PCPs strongly agreed with the addition of an LABD to the treatment regimen of a patient with stage 2-3 COPD experiencing dyspnea despite use of a short-acting bronchodilator. This discrepancy between self-reported practice recommendation and outcome expectancy is somewhat surprising since more than two-thirds of respondents indicated that the use of an LABD in such a patient would be extremely helpful in reducing exertional dyspnea, increasing overall activity level, and improving quality of life. Perhaps our findings on physician attitudes toward LABDs are tempered by studies contemporary to ours that reported potential adverse effects from LABD use. ${ }^{20-22}$ Clinicians may place more weight on mortality reduction as an indication for therapy, hence the low rate of strong agreement with use of an LABD for COPD.

\section{Limitations of the study}

In light of our findings, the model that we used to identify potential barriers to guideline adherence may have, in retrospect, omitted some important components. The finding of integration of office-based spirometry into patient flow as a significant barrier suggests that we may not have included certain factors to understand why spirometry is perceived to have low utility. Due to space constraints within the instrument, our LABD model was less comprehensive than the spirometry model and may have left out relevant barriers and other determinants of adherence (such as cost-benefit and contradictory evidence-based information).

Adherence was measured only by physician self-reporting and not corroborated by chart audits or other external checks. Physicians have been shown to have a limited ability to accurately self-assess; ${ }^{23}$ thus, the accuracy of our self-efficacy and adherence data may be limited. This study was conducted among mainly community-based PCPs who quickly responded to an invitation to participate. Although the sample differed somewhat from the overall population of PCPs within the AMA Physician Masterfile in terms of gender, it was statistically similar on all other parameters measured. With similar demographics and the use of 500 as a representative sample, there is no reason to believe that the perceptions of respondents are significantly different from those of the overall PCP population. Furthermore, the study findings are aligned with previously reported findings that self-efficacy, outcome expectancies, and external barriers may be more influential determinants of guideline adherence than simple guideline familiarity. Given the aforementioned limitations, this is the first study to our knowledge to use 
a framework such as Cabana et al's in examining barriers to COPD guideline adoption.

\section{Clinical implications}

Findings from this study offer some useful guidance in improving adherence to COPD guidelines. COPD guidelines appear to be less well known than guidelines for other prevalent diseases. Although guideline familiarity was not a predictor of adherence in the model, it may nevertheless be an early prerequisite. Efforts to increase the legitimacy and utility of this guideline for PCPs may be important. To improve guideline adoption, attitudes that can facilitate or impede guideline adoption must also be targeted. Agreement with guideline recommendations was a significant predictor of adherence. However, 1 in 5 PCPs reported ambivalence or disagreement with recommendations, and many were unconvinced that implementing recommendations would be beneficial. Information about specific recommendations must therefore simultaneously demonstrate the basis for the recommendation and its utility in the primary care setting.

Inadequate confidence in interpreting spirometry data may limit the utility of testing, and in this study was an independent predictor of nonadherence. Low confidence levels were rare, but more than 1 in 3 PCPs had only moderate confidence in their spirometry interpretation skills. This may reflect a synthesis, rather than a knowledge gap, and may point to difficulty in understanding how spirometry data relate to other clinical findings and improve diagnostic accuracy. To an extent, guidelines may be able to elaborate on the application of spirometry results in practice, but additional opportunities that allow PCPs to practice and refine spirometry interpretation skills may also be needed.

This study drew attention to the importance of measuring therapeutic response. Physicians who have difficulty gauging how patients have responded to therapy were somewhat less likely to adhere to recommendations on LABD use. LABDs may produce subtle, but meaningful, improvements during activity and may reduce exacerbation risk. PCPs may need more information regarding how LABDs improve respiratory health as well as tools that allow them to gauge improvement.

\section{Acknowledgements}

The authors would like to thank Dr Farrokh Sohrabi, Dr Dorcas Mansell, and the COPD Foundation for their assistance in this study and manuscript. This study was supported by Boehringer-Ingelheim Pharmaceuticals, Inc.

\section{Disclosure}

The authors report no conflicts of interest in this work.

\section{References}

1. Barr RG, Celli BR, Martinez FJ, et al. Physician and patient perceptions in COPD: the COPD Resource Network Needs Assessment Survey. Am J Med. 2005;118(12):1415.

2. Foster JA, Yawn BP, Abdolrasulnia M, et al. Enhancing COPD management in primary care settings. Med Gen Med. 2007;9(3):24.

3. Yawn BP, Wollan PC. Knowledge and attitudes of family physicians coming to COPD continuing medical education. Int J Chron Obstruct Pulmon Dis. 2008;3(2):311-317.

4. Pierson DJ. Clinical practice guidelines for chronic obstructive pulmonary disease: a review and comparison of current resources. Respir Care. 2006;51(3):277-288.

5. Tinkelman DG, Price DB, Nordyke RJ, Halbert RJ. Misdiagnosis of COPD and asthma in primary care patients 40 years of age and over. J Asthma. 2006;43(1):75-80.

6. Lee TA, Bartle B, Weiss KB. Spirometry use in clinical practice following diagnosis of COPD. Chest. 2006;129(6):1509-1515.

7. Damarla M, Celli BR, Mullerova HX, Pinto-Plata VM. Discrepancy in the use of confirmatory tests in patients hospitalized with the diagnosis of chronic obstructive pulmonary disease or congestive heart failure. Respir Care. 2006;51(10):1120-1124.

8. Kaminsky DA, Marcy TW, Bachand M, Irvin CG. Knowledge and use of office spirometry for the detection of chronic obstructive pulmonary disease by primary care physicians. Respir Care. 2005;50(12): 1639-1648.

9. Enright PL, Crapo RO. Controversies in the use of spirometry for early recognition and diagnosis of chronic obstructive pulmonary disease in cigarette smokers. Clin Chest Med. 2000;21(4): 645-652.

10. Cabana MD, Rand CS, Powe NR, et al. Why don't physicians follow clinical practice guidelines? A framework for improvement. JAMA. 1999;282(15):1458-1465.

11. Cabana MD, Rand CS, Becher OJ, Rubin HR. Reasons for pediatrician nonadherence to asthma guidelines. Arch Pediatr Adolesc Med. 2001; 155(9):1057-1062.

12. Cabana MD, Kim C. Physician adherence to preventive cardiology guidelines for women. Womens Health Issues. 2003;13(4): 142-149.

13. Cabana MD, Rushton JL, Rush AJ. Implementing practice guidelines for depression: applying a new framework to an old problem. Gen Hosp Psychiatry. 2002;24(1):35-42.

14. Rabe KF, Hurd S, Anzueto A, et al. Global strategy for the diagnosis, management, and prevention of chronic obstructive pulmonary disease: GOLD executive summary. Am J Respir Crit Care Med. 2007;176(6): 532-555.

15. Christian AH, Mills T, Simpson SL, Mosca L. Quality of cardiovascular disease preventive care and physician/practice characteristics. J Gen Intern Med. 2006;21(3):231-237.

16. Qaseem A, Snow V, Shekelle P, et al. Diagnosis and management of stable chronic obstructive pulmonary disease: a clinical practice guideline from the American College of Physicians. Ann Intern Med. 2007;147(9):633-638.

17. American Thoracic Society/European Respiratory Society Task Force. Standards for the Diagnosis and Management of Patients with COPD. 2005;2009(7/20/09):222.

18. Walters JA, Hansen EC, Johns DP, et al. A mixed methods study to compare models of spirometry delivery in primary care for patients at risk of COPD. Thorax. 2008;63(5):408-414.

19. Zwar N, Hermiz O, Hasan I, et al. A cluster randomised controlled trial of nurse and GP partnership for care of chronic obstructive pulmonary disease. BMC Pulm Med. 2008;8:8. 
20. Wedzicha JA, Calverley PM, Seemungal TA, et al. The prevention of chronic obstructive pulmonary disease exacerbations by salmeterol/ fluticasone propionate or tiotropium bromide. Am J Respir Crit Care Med. 2008;177(1):19-26.

21. Calverley PM, Anderson JA, Celli B, et al. Salmeterol and fluticasone propionate and survival in chronic obstructive pulmonary disease. N Engl J Med. 2007;356(8):775-789.
22. Nelson HS, Weiss ST, Bleecker ER, et al; SMART Study Group. The Salmeterol Multicenter Asthma Research Trial: a comparison of usual pharmacotherapy for asthma or usual pharmacotherapy plus salmetrol. Chest. 2006;129(1):15-26.

23. Davis DA, Mazmanian PE, Fordis M, et al. Accuracy of physician self-assessment compared with observed measures of competence: a systematic review. JAMA. 2006;296(9):1094-1102.

International Journal of COPD

\section{Publish your work in this journal}

The International Journal of COPD is an international, peer-reviewed journal of therapeutics and pharmacology focusing on concise rapid reporting of clinical studies and reviews in COPD. Special focus is given to the pathophysiological processes underlying the disease, intervention programs, patient focused education, and self management protocols.

\section{Dovepress}

This journal is indexed on PubMed Central, MedLine and CAS. The manuscript management system is completely online and includes a very quick and fair peer-review system, which is all easy to use. Visit $\mathrm{http}: / /$ www.dovepress.com/testimonials.php to read real quotes from published authors.

Submit your manuscript here: http://www.dovepress.com/international-journal-of-copd-journal 